Mini Review

\title{
Progress on Synthesis and Applications of Porous Carbon Materials
}

\author{
Bowen Li, He Xiong, Yang Xiao*, \\ Key Laboratory of Catalysis and Energy Materials Chemistry of Ministry of Education \& \\ Hubei Key Laboratory of Catalysis and Materials Science, South-Central University for Nationalities, \\ Wuhan 430074, China \\ *E-mail: xiaoyang@scuec.edu.cn
}

doi: $10.20964 / 2020.02 .04$

Received: 2 September 2019 / Accepted: 31 October 2019 / Published: 31 December 2019

\begin{abstract}
Porous carbon materials have been applied in a tremendous amount of fields recently for their various pore structures and larger specific surface area compared to other materials. They can be synthesized with low pollution and well controlled in pore size and channel. Particularly, they have high use period in cycle, chemical inertness in interface, strong mechanical strength in structure and good performance in electrical conductivity. This review summarizes several synthesis methods of porous carbon materials and applications in electrochemistry, hydrogen storage, catalyst support and gas adsorption and separation of porous carbon materials. Porous carbon materials have been further explored on using ecofriendly methods to synthesize porous carbons and directions for future research on porous carbons. The tip of the iceberg with respect to the application potential of them is just emerged. A base help was provided for further investigations into applications of porous carbons.
\end{abstract}

Keywords: porous carbon, synthesis, application, supercapacitor, hydrogen storage

\section{$\underline{\text { FULL TEXT }}$}

(C) 2020 The Authors. Published by ESG (www.electrochemsci.org). This article is an open access article distributed under the terms and conditions of the Creative Commons Attribution license (http://creativecommons.org/licenses/by/4.0/). 